\title{
Ética comunicativa y bioética
}

PROF. DR. D. JOSE DELGADO PINTO

Catedrático de Filosofia del Derecho, Universidad de Salamanca

1. Poco tiempo antes de recibir la invitación de la profesora Ana María Marcos a participar en estas Jornadas tuve noticia de la publicación del libro de J. Habermas El futuro de la naturaleza humana ¿̈Hacia una eugenesia liberal? (trad. de la edic alemana -Frankf. a. M., Suhrkamp, 2001Barcelona, Paidos, 2002), en el que el filósofo alemán aborda algunos de los problemas morales que plantean los actuales avances de la tecnología genética. De este modo, al ser invitado, pensé que sería interesante exponer y examinar las tesis defendidas en el libro citado. El interés viene avalado por la personalidad del autor. Habermas, como es sabido, es uno de los más importantes filósofos contemporáneos. Junto con unos pocos más, entre los que se cuenta el recientemente fallecido J. Rawls, constituye punto de referencia inexcusable del pensamiento público internacional. Es importante, no sólo en el plano de la ontología y de la epistemología, sino también, y sobre todo, en el de la filosofía práctica -moral, jurídica y política. La ética comunicativa o discursiva, defendida por él junto con K.O. Apel, representa la expresión teórica más solvente del ideal moral de la modernidad, desprendido de todo 
apoyo en las tradiciones religiosas y metafísicas, pero que se mantiene firme frente a la deriva relativista de las diversas tendencias del postmodernismo. Siendo así, creo que tiene interés, en efecto, examinar qué es lo que tal filosofía moral tiene que decir sobre problemas tan graves como los que plantea la aplicación de las tecnologías genéticas a la vida de los seres humanos: cómo enfoca la cuestión, qué aciertos pueden reconocérsela, cuáles son sus limitaciones.. Esto es lo que, resumidamente, me propongo exponer. Comenzaré refiriéndome de forma esquemática al sentido de la ética comunicativa de Habermas para pasar a ver, después, cómo enfoca y resuelve el problema de la aplicación de la tecnología genética a la especie humana.

2. La ética comunicativa o discursiva constituye una ética de inspiración kantiana; es una reconstrución de la filosofía moral de Kant, depurada de aquellos amarres a la metafísica que la filosofía de los dos últimos siglos creía todavía presentes en el pensamiento del filósofo de Kónisberg.

Al igual que la de Kant, la ética de Habermas es una ética racionalista o, si se quiere, cognitivista. Se enfrenta así a las diversas formas de irracionalismo para las que nuestros juicios morales son mera expresión de sentimientos o emociones y, del mismo modo, rechaza los distintos tipos de relativismo moral. Frente a estas corrientes sostiene con firmeza la capacidad de la razón humana para determinar de forma intersubjetivamente válida qué es lo bueno y lo malo, lo justo y lo injusto.

Pero, al mismo tiempo se trata de una ética deontológica y puramente procedimental. Deontológica porque, según ella, la bondad o maldad moral de las acciones, su rectitud o no rectitud, no depende de que sean, o no sean, el medio adecuado para alcanzar algún bien fundamental -la felicidad, la plenitud o perfección, la utilidad común,etc.sino de que se ajusten, o no, a un criterio de rectitud, a un principio o norma que la filosofía moral debe determinar. Según este enfoque las cuestiones so- 
bre el bien de la vida humana, su plenitud, la felicidad o la vida buena, no son cuestiones que la filosofía moral pueda resolver de forma vinculante para todos, sino que, como volveremos a decir, son cuestiones que reciben respuestas diversas según las distintas concepciones del mundo.

Como he dicho, para Habermas la filosofía moral ha de dilucidar cuál es el criterio o principio de la moralidad de las acciones. Su tarea consiste en discutir y poner en claro cuál es el procedimiento adecuado para determinar qué normas o qué acciones son moralmente buenas o debidas y cuáles malas o indebidas, pero no le compete ya aplicar dicho criterio a éstas o las otras normas o acciones concretas. En esta limitación de su tarea a la fundamentación del criterio o principio de la moralidad radica el carácter procedimental de esta ética, aunque es dicutible que Habermas se haya atenido estrictamente a tal limitación.

Las características señaladas: racionalismo 0 cognitivismo, deontologismo, procedimentalismo, las comparte la ética habermasiana con otras tendencias éticas contemporáneas de raigambre kantiana. Lo que la distingue y le da nombre -ética comunicativa o discursiva- es el peculiar procedimiento que considera adecuado para dilucidar la bondad o maldad, la rectitud o no rectitud, y que consiste en un cierto diálogo, discurso o argumentación. Intentaré exponerlo de forma esquemática y simplificada, partiendo de un parangón con Kant.

Como es sabido, Kant parte del "factum" de la conciencia moral individual, de la presencia de la ley moral en todo ser humano. Y como criterio para determinar la moralidad de las acciones propone el principio de universalización, el imperativo categórico: para saber si obra correctamente el sujeto individual debe dilucidar si la máxima, o regla, que sigue en unas circunstancias dadas puede convertirse en ley universal para todos los seres racionales. Habermas (al igual que K.O. Apel) considera que el punto de partida de Kant implica ciertas presuposiciones metafísicas, y que el procedimiento del imperativo categórico peca de subjetivismo solipsista. Por eso se propone llevar a cabo una reconstrucción comunicativo-dialógica de la ética kantiana. 
El "factum" o hecho fundamental del que parte es el hecho de la interacción social a través del lenguaje. La consciencia de sí mismo como persona responsable, como sujeto moral, la alcanza el hombre como resultado del proceso de socialización, cuando participa en la vida de relación con los otros a los que reconoce como sustancialmente iguales, siendo él a su vez reconocido como tal. Es en ese medio de las relaciones sociales cotidianas a través del lenguaje donde los deseos e intereses de los individuos se coordinan, haciendo posible la cooperación; pero también es posible que tales deseos e intereses entren en conflicto. Los problemas morales surgen cuando en situación de conflicto se plantea la cuestión de qué intereses o cursos de acción han de considerarse correctos y, por tanto, debidos u obligatorios para todos, y cuáles no.

Para determinar el criterio o procedimiento para dirimir lo moralmente correcto de lo incorrecto Habermas parte de un análisis que pone al descubierto los presupuestos implícitos en lo que él llama la acción comunicativa. La acción comunicativa es una forma de interacción social prioritaria respecto de cualesquiera otras, como la acción instrumental o la acción estratégica, porque hace posible el acuerdo inicial entre los hombres sin el cual cualquier tipo de cooperación sería impensable. El análisis muestra que en la acción linguística comunicativa se encuentra implícita una serie de pretensiones validez como, entre otras, la pretensión de verdad de nuestros enunciados sobre cómo es el mundo, cómo son las cosas, y la pretensión de rectitud de nuestras exigencias respecto de nuestra conducta o la de los demás. Ambas pretensiones, si se mantienen seriamente, remiten como fundamento o justificación a un consenso racional.

Esta remisión permanece implícita cuando la interacción social discurre sin problemas, de forma que los participantes aceptan la pretensión de verdad de las informaciones que intercambian y la justicia o rectitud de la exigencias de conducta en cuanto basadas en normas generales compartidas. Sin embargo, se hace explícita cuando surge el conflicto y la cooperación normal se quiebra, siendo necesario restaurar 
el consenso mediante el procedimiento del discurso.. "Discurso" llama Habermas a una forma de acción comunicativa pura, destinada a dirimir las pretensiones de validez que se han vuelto problemáticas. En el discurso teórico argumentamos mediante explicaciones a fin de restaurar el consenso sobre la verdad de los enunciados. En el discurso práctico argumentamos a fin de restaurar el consenso sobre la legitimidad de las normas que regulan la interacción social, y discutimos sobre necesidades e intereses, intentando probar que se trata de intereses o necesidades comunes, generales.

En todo caso, el discurso consiste en un proceso de argumentación en el que se dejan de lado las compulsiones inmediatas de la acción, para intercambiar razones con el fin de alcanzar un consenso. Sobre esta base se puede decir que una norma se considera fundamentada, o justificada, en la medida en que puede ser objeto de un consenso racional. Ahora bien, hay que advertir que consenso racional no significa cualquier acuerdo al que pueden llegar quienes discuten o negocian, sino que designa el acuerdo logrado tras un proceso deliberativo sometido a una serie de reglas que definen lo que se llama una situación ideal de habla . Aquí solo puedo mencionar, por vía de ejemplo, algunas de esas reglas, como la que exige la participación de todos los interesados y la posibilidad de que cada cual pueda alegar lo que estime pertinente; la de que todos puedan disponer de la información necesaria; la que requiere que la deliberación se desarrolle en términos de estricta igualdad, sin subordinaciones ni coacciones por parte de nadie; etc.

Como se ha advertido repetidamente, ese conjunto de reglas muy difícilmente se puede cumplir, o satisfacer, en las situaciones sociales reales en las que se discute sobre problemas morales y políticos. Por eso la situación ideal de habla es precisamente eso, un "ideal"; y el consenso racional que habría que alcanzar tiene un sentido utópico. Pese a todo, en cuanto presupuesto normativo implícito en toda argumentación moral que emprendemos en serio, actúa como idea regulativa, como orientación de nuestras deliberaciones encaminadas a justificar normas, 
y como canon para la crítica de nuestros diálogos reales. Dado que el consenso racional no es plenamente alcanzable en la práctica, el discurso práctico, o argumentación racional intersubjetiva, como procedimiento para determinar la rectitud de las normas morales, sólo puede conducir a resultados falibles. En todo caso, con esta reserva, vale la afirmación de que un juicio moral o una norma se pueden considerar válidos, fundamentados, si pueden ser aceptados por todos a los que afecta en cuanto participantes en un discurso práctico.

Con lo dicho hasta aquí creo que quedan expuestas, aunque sea de una forma apresurada, las ideas centrales de la ética comunicativa o discursiva de Habermas. Sin embargo, para entender su posición respecto de los problemas que plantea la biotecnología, conviene insistir en un rasgo de la misma al que ya aludí de pasada cuando la califiqué como ética dentológica, y al que el propio Habermas se refiere diciendo que su filosofía moral es postmetafisica. Cuando dice esto quiere decir que se trata de una filosofía moral estrictamente racional, que se apoya exclusivamente en la razón dialógica, desprendiéndose de cualquier apoyo en tradiciones o autoridades, confesiones religiosas o concepciones del mundo. Haciendo hincapié en este carácter postmetafísico, nuestro autor distingue entre el enfoque o punto de vista moral y las cuestiones morales, por un lado, y, por otro, el enfoque ético y las cuestiones éticas, entendiendo ética en el sentido clásico de lo necesario para alcanzar la vida buena, plena o perfecta.

Una cuestión moral puede ser cualquier cuestión que surja en la convivencia social cuando a propósito de ella las pretensiones de uno acerca de qué es lo correcto, lo debido, entran en conflicto con las pretensiones de otro, u otros. Los conflictos morales tienen que ser planteados y resueltos desde el punto de vista del nosotros, es decir, del conjunto de los participantes en la deliberación racional tendente a encontrar una solución; y ésta será una solución vinculante u obligatoria para todos. Por otro lado, en la deliberación sólo cuentan las razones morales, es decir, razones que pueden ser aceptables para todos en cuanto partici- 
pantes en un diálogo racional, quedando excluidas aquellas razones o argumentos determinados por creencias o convicciones particulares no compartibles por todos.

Por su parte las cuestiones éticas son aquellas que tienen que ver con lo que se debe hacer u omitir para alcanzar una vida lograda, perfecta o feliz. Ahora bien, en qué consista una vida lograda, perfecta o feliz depende de la concepción del mundo que se mantenga y, dentro de ella, del sentido que se atribuya a la existencia humana. Y como las concepciones del mundo y de la existencia humana son diversas, los conflictos sobre cuestiones éticas, a diferencia de los conflictos morales, no admiten soluciones generales vinculantes para todos. En nuestras sociedades contemporáneas pluralistas, dice Habermas, la filosofía moral postmetafísica debe permanecer neutral respecto de las diversas concepciones del mundo, religiosas o laicas. Aunque las cuestiones éticas a menudo revisten la máxima importancia para los seres humanos, la filosofía moral ha de abstenerse de tomar partido sobre las mismas y ha de mantenerse en el plano de una moral racional válida para todos.

3. Es a partir de esta concepción de la filosofía moral, de su tarea y de sus límites, como Habermas aborda los temas de la bioética. Según ciertos indicios la ocasión que determinó que se ocupara de esta materia fue una ponencia que el también filósofo alemán Peter Sloterdijk expuso en un simposio internacional de filosofía en julio de 1999 y que dio lugar a un gran revuelo en Alemania. Dicha ponencia llevaba por titulo Reglas para el parque humano. Un escrito de respuesta a la carta sobre el humanismo de Heidegger ("Regeln für den Menschenpark. Ein Antwortschreiben zu Heideggers Brief über den Humanismus"). En ella venía a sostener que, dada la imposibilidad contemporánea del humanismo, filósofos y biólogos deberían ponerse de acuerdo para el tratamiento genético de la especie humana. El revuelo que se produjo en los ambientes intelectuales germanos se explica porque las tesis de Sloter- 
dijk evocaban los ensayos eugenésicos de la época nazi. Dicho revuelo, en el que indirectamente se vio envuelto Habermas, fue con toda probabilidad lo que determinó que éste se ocupara de una temática a la que hasta hace un par de años había permanecido ajeno.

Ahora bien, hay que añadir que la ocasión que dio lugar a la reflexión de Habermas sobre las cuestiones de la bioética determinó también que se centrara en el tema de la licitud de la eugenesia. Esto no quiere decir que ignore todos los demás problemas de la bioética. Se refiere, por ejemplo, a la polémica mantenida en los últimos decenios sobre el aborto, comentando las distintas posiciones que se han sostenido. Asimismo alude a la cuestión de la eutanasia y a los problemas colaterales que pueden surgir de una permisión parcial de la misma. Sobre todo le preocupan las cuestiones que pantean las nuevas posibilidades de intervención resultantes de la confluencia de los avances de la medicina reproductiva y la investigación genética. Desde que se consiguió separar algunos componentes elementales de un genoma y combinarlos de nuevo, la técnica genética ha acelerado su desarrollo. Por otro lado, la fecundación "in vitro" ha permitido investigar y experimentar en el ámbito de la genética humana con celulas madre fuera del cuerpo materno. La coincidencia de la medicina reproductiva y la técnica genética ha dado lugar al diagnóstico de preimplantación: una prueba genética a la que se somete al embrión en un estadio precoz de desarrollo para decidir, según el resultado de la prueba, si se implanta para que siga desarrollándose o se desecha. También ha permitido la investigación con embriones con diversos fines; usualmente se destacan los fines curativos como el cultivo de tejidos para el trasplante de órganos, la posible intervención correctiva en el genoma para evitar enfermedades graves condicionadas genéticamente, etc.; pero también es posible la intervención con fines proyectivos o manipuladores, para condicionar en un sentido u otro la dotación genética de futuros seres humanos.

Estos últimos son los problemas sobre los que centra su atención $\mathrm{Ha}$ bermas, preguntándose qué puede decir la moral a propósito de los mis- 
mos y cuál debería ser, en consecuencia, su regulación jurídica. Nuestro autor es consciente de la extrema dificultad de someter a reglas el avance progresivo de la biotecnología. Sabe cuán poderosas son las fuerzas que propugnan i a libertad de investigar y de aplicar las nuevas técnicas que se van descubriendo: el afán de los científicos por obtener nuevos decubrimientos; los poderosos intereses económicos que estan detrás de la actividad investigadora, en especial los de las industrias farmacéuticas; el progresismo indicriminado de muchos medios de comunicación; etc. Reconoce la dificultad de regular una actividad que avanza tan rápidamente, y en la que es muy difícil trazar una frontera nítida entre técnicas que se proponen objetivos médico-curativos y técnicas manipuladoras no orientadas a la curación. Por otro lado, hasta ahora el avance tecnológico ha favorecido, en general, el bienestar de los seres humanos, aumentando sus posibilidades de acción, su autonomía; por lo que, en cuanto la investigación biogenética promete el alargamiento de la vida o la curación de enfermedades, con seguridad gozará del favor del público. Por eso mismo resulta fácil considerar las propuestas de establecer criterios morales y jurídicos a los que debieran someterse las nuevas tecnologías como intentos reaccionarios de limitar la libertad propia de las sociedades modernas en nombre de una arcaica resacralización de la naturaleza humana. Sin embargo, Habermas proclama enfáticamente la necesidad de que el pensamiento moral y político lleve a cabo una reflexión pública sobre el conjunto de las investigaciones biogenéticas, para no ir como hasta ahora a remolque de los hechos consumados. Y subraya que la pretensión de someter las nuevas tecnologías a criterios morales bien fundados es congruente con la idea una modernidad que se ha hecho reflexiva y procura conservar las condiciones que hacen posible la misma libertad frente a potenciales amenazas provenientes de una eugenesia liberal.

Porque, en definitiva, como ya apunté más arriba, lo que fundamentalmente preocupa a Habermas es la posibilidad de una eugenesia liberal. Aunque también considera otras cuestiones, acaba centrando su 
atención en el problema que supondría la utilización de las técnicas biogenéticas con fines eugenésicos, es decir, con el fin de seleccionar y modificar las marcas o rasgos característicos de la herencia genética de los individuos humanos. A estos efectos Habermas distingue claramente entre la variedad autoritaria de la eugenesia y la variedad liberal. La primera tiene un sentido colectivista y elitista, e implica la intervención del poder político en las prácticas reproductivas con el fin de mejorar la especie en función de un modelo prefijado. Este tipo de eugenesia, que gozó de amplio favor en diversos países en el primer tercio del siglo XX, choca en nuestros días con convicciones morales y políticas mayoritariamente compartidas. En cambio, se está abriendo camino una posible eugenesia liberal, descentralizada, conforme a la cual serían el mercado, regido por el interés de maximizar los beneficios, y las preferencias de los demandantes, los futuros padres fundamentalmente, quienes determinarían las intervenciones a realizar para mejorar la dotación genética de los seres humanos por nacer. Sus defensores afirman que mientras que la eugenesia autoritaria limitaba las libertades habituales en materia de procreación, la liberal las aumentaría radicalmente. Pues bien, la pregunta central en torno a la que gira el ensayo de Habermas es la de si tal eugenesia liberal es moralmente aceptable o rechazable, si las intervenciones eugenésicas se deben permitir libremente o debieran someterse a alguna regulación.

El propio Habermas subraya que sus reflexiones constituyen más un ensayo que intenta desenmarañar unas cuantas intuiciones básicas, que un tratamiento definitivo de la cuestión. Y, en efecto, en ocasiones su discurso parece vacilante, no concluyente. Con todo, creo que la respuesta final es clara: no es admisible una eugenesia liberal sin ningún límite, pues la alteración deliberada de la herencia genética humana, salvo cuando obedece a la finalidad de evitar enfermedades graves, pone en peligro el presupuesto mismo sobre el que se sustenta la vida moral. Trataré de exponer la argumentación de Habermas de la forma más clara y concisa que me sea posible. 
4. Como he sugerido, nuestro autor parte de la intuición de que una eugenesia liberal sin límites no es admisible, pues pone en peligro la base sobre la que se sustenta nuestra vida moral, entendida como un forma de vida en la que seres autónomos se dan normas vinculantes para todos. Tal forma de vida parece requerir la no disponibilidad de los fundamentos biológicos de la identidad de las personas o, visto desde otro ángulo, la integridad de unas disposiciones hereditarias no manipuladas como asiento de la propia autonomía moral. Por tanto, debe protegerse esa integridad de una herencia genética no manipulada. Lo que intenta Habermas es formular una argumentación que apoye esta intuición de la que parte.

Ante todo considera que, según su forma de entender la moralidad, no es posible utilizar un único argumento contundente de naturaleza moral, como el que consistiría en atribuir al embrión humano la dignidad propia de las personas y, en consecuencia, la inviolabilidad, que excluiría cualquier manipulación e instrumentalización. Hacerlo así implicaría tomar partido por una determinada concepción del mundo y de la vida humana que, en nuestras sociedades pluralistas, puede estar en conflicto con otras concepciones. Y una moral estrictamente racional, postconvencional y postmetafísica, debe ser neutral respecto de tales concepciones. Conforme a dicha moral, sólo los sujetos que se relacionan entre sí dialógicamente, capaces de obligarse de forma recíproca, son los que pueden reconocerse unos a otros como personas dotadas de dignidad y, por tanto, de inviolabilidad' Cualquier otra entidad puede constituir un bien de mayor o menor valor; puede incluso poseer un valor tan alto que no quepa disponer de él libremente; pero la razón de esta indisponibilidad no será la atribución a dicha entidad de la dignidad e inviolabilidad que corresponde sólo a las personas morales.

De acuerdo con lo dicho, la vida del embrión humano debe considerarse como un bien entre otros. Pero no se trata de un bien ponderable e intercambiable con cualquier otro. Es posible argumentar en favor de considerarlo como un bien del que no puede disponerse libremente. Es 
verdad que el valor que se atribuye al embrión varía según las concepciones éticas: desde considerarlo como una "res sacra", según algunas concepciones religiosas, hasta considerarlo como un "montón de células", según el cientificismo naturalista. Sin embargo, no se trata en este caso de una cuestión ética como cualquier otra cuya valoración varía según las culturas y concepciones del mundo. Pues se trata de una cuestión que afecta a la imagen que tenemos de nosotros mismos en cuanto seres humanos, en cuanto especie. Ciertamente, se puede decir que la imagen que tenemos de nosotros mismos como especie varía también según las diversas éticas y concepciones del mundo; y recordar que la moral estrictamente racional, postmetafísica, no puede apoyarse en una concepción de mundo o en una ética

Según Habermas lo que convierte al niño en persona desde el momento del nacimiento es el acto socialmente individualizador de acogerlo en el contexto público de interacción de un mundo de la vida compartido intersubjetivamente. Cfr. op. cit. 52-53.

determinada. Sin embargo, Habermas sostiene que la moral racional abstracta de sujetos que se reconocen unos a otros como personas se apoya en una autocomprensión ética de la especie, compartida por todas las personas morales. Esta autocomprensión de nosotros mismos como especie viene a ser como un entorno ético estabilizador para la moral racional; de forma que su alteración o desaparición probablemente implicaría la desaparición de la vida moral misma.

Lo que hay que preguntarse es si la manipulación de la herencia genética humana altera o amenaza, o no, esa autocomprensión ética de la especie que sustenta a la moral. La respuesta de Habermas es que sí. Por tanto, frente a los defensores de una eugenesia liberal, sostiene que debe protegerse la integridad de unas disposiciones hereditarias no manipuladas, salvo cuando se trate de intervenciones médicas orientadas a la evitación de enfermedades graves. Sobre esta base la protección jurídica podría articularse como un derecho a una herencia genética en la que 
no se haya intervenido artificialmente, salvo los casos aludidos de interveciones médicas curativas.

Ahora bien, ¿en qué consiste esa autocomprensión ética de la especie, esa forma de comprendernos a nosotros mismos que, en opinión de Habermas, fundamenta y posibilita la vida moral? En cuanto participantes en esa forma de vida nos vemos como seres autónomos y fundamentalmente iguales. Autónomo en este contexto significa dueño único del propio destino personal, de la propia biografía, responsable por las decisiones que toma. En cuanto responsable, uno se considera capaz de deliberar con los demás y de asumir obligaciones recíprocas. $Y$ en este sentido se considera fundamentalmente igual a cualquier otro.

Esta autocomprensión se mantiene mientras la dotación genética heredada es algo natural, fruto de un crecimiento orgánico azaroso, no programado. El ser humano asume su herencia genética, como asume también críticamente la educación recibida y la influencia del medio social y, a partir de esa asunción crítica, puede considerarse dueño de sus propias decisiones, en un plano de igualdad básica con los demás. Sin embargo, cuando, debido a la manipulación genética, se desdibuja la distinción entre lo natural, crecido orgánicamente, y lo construído como un artefacto programado, aquella autocomprensión se ve alterada y ya no parece plausible que el sujeto cuya herencia genética ha sido programada se considere a sí mismo, en igualdad con los demás, como dueño y responsable único de su destino personal. Habermas alude a un texto de R.Dworkin en el que éste afirma que la separación clara entre lo que somos por herencia, en lo que interviene la casualidad, y las decisiones que a partir de ahí tomamos y de las que somos responsables, constituye la espina dorsal de nuestra experiencia moral; y añade que ésta se vería alterada si se llegara a una programación de la herencia genética.

Esta idea se ve confirmada y expresada de forma más concreta si centramos nuestra mirada en la relación que se establecería entre padres e hijos si aquéllos decidieran que se interviniese y se condicionase en al- 
gun sentido la herencia genética de éstos. Se consolidaría entonces una relación de dominio intergeneracional que sería irreversible, a diferencia de lo que ocurre en la relación normal entre padres e hijos. En ésta es usual que se de una subordinación de los hijos a los padres que se prolonga durante el período de crianza y educación. Pero se trata de una relación de subordinación reversible. Pues lo normal es también que, a partir de la adolescencia, los jóvenes sometan a cuestionamiento crítico la educación recibida, asumiendo o rechazando unas pautas $u$ otras, constituyéndose así en personas adultas responsables de sus propias decisiones. Sin embargo, cuando por decisión de los padres se hubiesen condicionado genéticamente las tendencias o aptitudes de sus descendientes no sería posible una rectificación ulterior. Se consolidaría así una relación instrumentalizadora de los hijos, un paternalismo intergeneracional irreversible. $Y$ de este modo se vería amenazada, o irremediablemente alterada, aquella comprensión de nosotros mismos como seres autónomos y fundamentalmente iguales en que se sustenta nuestra vida moral.

Según Habermas, esa relación de dependencia no consentida e irreversible no se daría cuando la intervención en la herencia genética se llevara a cabo con fines curativos, para evitar enfermedades muy graves. Pues en este caso la relación resultante sería similar a la que se establece entre médico y enfermo, una relación interpersonal en la que cuenta el consentimiento del paciente. Se podría objetar que es absurdo hablar de relación interpersonal y de consentimiento del paciente siendo así que la intervención se realizaría en un embrión. Sin embargo, señala nuestro autor, es lícito suponer contrafácticamente dicho consentimiento cuando se trata de evitar enfermedades generalmente consideradas como muy graves.

Los defensores de una eugenesia liberal aducen que la dotación genética de un individuo interactúa con el entorno, con las circunstacias ambientales, de una forma contingente, aleatoria; de manera que la alteración deliberada de aquélla no se traduce necesariamente en una li- 
mitación de la libertad de acción de la persona, en una modificación inadmisible de sus futuros planes de vida. Siendo así, añaden, no hay diferencia esencial entre la actividad de los padres orientada a mejorar el futuro de sus hijos por medio de la educación socializadora y su actividad orientada al mismo objetivo a través del condiciona miento genético. Y como a los padres se les reconoce el poder de hacer lo primero, así también debe reconocérseles el de hacer lo segundo.

Habermas rechaza esta argumentación, poniendo de relieve que existe una diferencia fundamental, con relevancia moral, entre la influencia ejercida a través de la educación y la ejercida a través de la intervención en la dotación genética. En ambos casos los padres imponen a los hijos cualidades o propiedades que consideran buenas y que éstos, alcanzado el suficiente desarrollo, valorarán también como buenas o rechazarán. Pero cuando se trata de la educación, a diferencia de lo que ocurre en el caso de la manipulación genética, la relación asimétrica de dominio de los padres respecto de los hijos es reversible. Como se indicó anteriormente, el joven puede equilibrar retrospectivamente la asimetría de la dependencia infantil mediante el cuestionamiento crítico de la educación recibida, constituyéndose así en persona dueña de su propio destino. Esto es lo que no es posible cuando se ha intervenido deliberadamente en la dotación genética del individuo, de manera que si, llegado a la edad adulta, se muestra disconforme con las cualidades o aptitudes impuestas, no le queda otra posibilidad que la resignación fatalista o el resentimiento.

Podemos resumir ahora brevente la posición de Habermas respecto del problema de la admisibilidad de la eugenesia liberal. Según su forma de entender la moralidad no es posible articular un argumento de naturaleza moral que, de forma directa, fundamente la prohibición de alterar deliberadamente la dotación genética humana; pues una moral estrictamente racional, postmetafísica, no ofrece una razón para considerar al embrión humano como una persona moral dotada de la correspondiente dignidad e inviolabilidad. La protección de la integridad de la 
herencia genética puede fundamentarse, sin embargo, en un argumento moral indirecto: el de que la manipulación genética, salvo cuando se emplea con fines curativos, amenaza con alterar la autocomprensión ética de la especie que sirve de sustento a nuestra forma de vida moral, es decir, amenaza la comprensión de nosotros mismos como seres autónomos, responsables de nuestras propias decisiones y, en este aspecto, fundamentalmente iguales. Por tanto, la protección de la vida moral misma requiere que se regulen las posibles intervenciones en la dotación genética humana. Habermas se cuida de advertir que estas reservas y exigencias de regulación no se refieren a la investigación y la invención técnica en sí mismas, sino a la intención o finalidad con que se usan.

5. En las páginas anteriores, tras resumir esquemáticamente los caracteres de la filosofía moral de Habermas, he expuesto las tesis que defiende sobre la cuestión de las intervenciones genéticas con fines eugenésicos. Las he expuesto de forma sintética y ordenada, evitando algunas complicaciones y circunloquios que se dan en el libro y que son perfectamente comprensibles en un ensayo escrito para responder a un problema de actualidad. Para terminar permítanme esbozar brevísimamente alguna valoración.

Lo primero que hay que decir, enlazando con el título de esta ponencia, es que Habermas no se ocupa de forma general y sistemática de los problemas de la bioética. Aparte de algunas alusiones inconclusas a varios asuntos, tales como el aborto, el llamado diagnóstico de preimplantación y el uso de embriones humanos para la investigación, su interés se centra en las intervenciones genéticas con fines eugenésicos. Esto no tiene nada de sorprendente, pues lo suyo es la filosofía moral, no la "ética aplicada". El que se haya ocupado de esa cuestión revela la importancia que le concede, que se corresponde por cierto con la transcendencia que objetivamente posee para una civilización que quiere cohonestar el progresivo avance de la ciencia y la tecnología con el 
mantenimiento de una forma de vida moral. Como subraya Habermas, no existen apenas tratamientos detallados de la cuestión que ofrezcan soluciones derivadas de una argumentación moral sólida. Esto concede mayor importancia al ensayo del filósofo alemán, que ofrece una solución que creo aceptable en términos generales, apoyándola en una argumentación acorde con los postulados de la filosofía moral estrictamente racional y postmetafísica que considera adecuada en nuestras sociedades pluralistas.

Sin perjuicio de lo que antecede, creo que la argumentación de $\mathrm{Ha}$ bermas pone al descubierto las limitaciones de esa filosofía moral. Ante todo, porque, como vimos anteriormente, de acuerdo con esa forma de entender la moralidad no es posible un argumento moral directo que apoye la limitación de las intervenciones modificativas de la herencia genética humana. Ese apoyo sólo resulta de una argumentación indirecta que pone en juego la autocomprensión ética de la especie que sirve de sustento a nuestra forma de vida moral. Pero, si llevamos adelante esa argumentación, nos sale al paso la pregunta crucial de por qué hemos de querer mantener la forma de vida moral, esa forma de vida en la que tienen sentido los juicios, actitudes y conductas morales. Y la respuesta a esta pregunta no puede venir de la moral misma, tal como la entiende esa filosofía. Una valoración de la moral como totalidad no puede ser ella misma un juicio moral, sino un juicio ético, de ética de la especie, al que, sin embargo, parece que no se podría atribuir la fuerza general vinculante que sólo correspondería a los juicios estrictamente morales. 